\title{
Effect of negative pressure ventilation on arterial blood gas pressures and inspiratory muscle strength during an exacerbation of chronic obstructive lung disease
}

\author{
J M Montserrat, J A Martos, A Alarcon, R Celis, V Plaza, C Picado
}

\begin{abstract}
The effects of intermittent negative pressure ventilation have been studied in 20 patients with chronic obstructive pulmonary disease during an exacerbation of their disease. Measurements of arterial blood gas tensions and maximal inspiratory pressure (MIP) were performed before and after six hours of negative pressure ventilation or standard treatment (control day) given in random order on two consecutive days. After negative pressure ventilation the mean (SD) value of MIP increased from $68 \cdot 1(21 \cdot 5)$ to $74.8(20) \mathrm{cm} \mathrm{H}_{2} \mathrm{O}^{\star}$ arterial oxygen tension $\left(\mathrm{PaCO}_{2}\right)$ fell from 60.6 $(12 \cdot 2)$ to $50.9(8.9) \mathrm{mm} \mathrm{Hg}$ but $\mathrm{PaO}_{2}$ changed little (from $48 \cdot 4(7 \cdot 4)$ to $47 \cdot 6(8 \cdot 2)$ mm $\mathrm{Hg})$. There were no significant changes on the control day in arterial blood gas tensions $\left(\mathrm{PaO}_{2} 47 \cdot 8(8 \cdot 1)\right.$ and $48.9(9.4)$ and $\mathrm{PaCO}_{2} 59.8(10.9)$ and 57.5 $(8.06) \mathrm{mm} \mathrm{Hg})$ or in MIP $(69.4(22.4)$ and $70.9(22.9)$ cm $\left.\mathrm{H}_{2} \mathrm{O}\right)$. Six patients tolerated negative pressure ventilation poorly and these patients showed less improvement after negative pressure ventilation. Our results suggest that intermittent negative pressure ventilation can increase alveolar ventilation in patients with an exacerbation of chronic obstructive lung disease, particularly in those who tolerate the procedure well. Most subjects showed a fall in $\mathrm{PaCO}_{2}$ and an increase in MIP. The fact that $\mathrm{PaO}_{2}$ was unchanged despite the fall in $\mathrm{PaCO}_{2}$ suggests that gas exchange may deteriorate with negative pressure ventilation in these patients.
\end{abstract}

Servei de Pneumologia, Hospital Clinic, C Villarroel 170, Barcelona 08036, Spain J M Montserrat J A Martos, A Alarcon $\mathrm{R}$ Celis V Plaza C Picado

Address for reprint requests: Dr Picado.

Accepted 14 October 1990 Intermittent negative pressure ventilation may lead to an improvement in arterial blood gases, dyspnoea, and inspiratory muscle strength. ${ }^{1-4}$ This improvement has been attributed to the resting of fatigued inspiratory muscles. Zibrak et $a l,{ }^{5}$ however, were unable to find such beneficial effects of negative pressure ventilation in a recent inves-

${ }^{\star}$ Conversion to $\mathrm{SI}$ units: $1 \mathrm{~cm} \mathrm{H} \mathrm{H}_{2} \mathrm{O}=0.1 \mathrm{kPa} ; 1 \mathrm{~mm}$ $\mathrm{Hg}=0.133 \mathrm{kPa}$. tigation, possibly because the poncho wrap negative pressure ventilation system they used was poorly tolerated. This suggests that discomfort might be an important limitation to the prolonged use of negative pressure ventilation.

We have been unable to find any report on the use of negative pressure ventilation during an exacerbation in patients with chronic obstructive lung disease. In theory, negative pressure ventilation might prevent hypoxaemia, hypercapnia, and the increase in ventilatory work that predisposes to respiratory muscle fatigue. For this reason we initiated a pilot study to assess acceptability and therapeutic effects of negative pressure ventilation in patients with chronic obstructive lung disease admitted to the respiratory ward during an exacerbation.

\section{Methods}

PATIENTS

Studies were carried out in 20 consecutive patients with chronic obstructive lung disease admitted to the respiratory ward because of hypercapnic respiratory failure due to an exacerbation attributed to bronchial infection. Patients with unstable cardiac disease or other active medical problems were excluded. The characteristics of the patients are summarised in table 1. The protocol was approved by the research committee of our hospital.

\section{INVESTIGATIONS}

Patients were enrolled in the study on their first or second day in hospital. Maximal inspiratory pressures (MIP) were measured with the subject seated by an aneroid manometer (Inspiratory Force Meter, model 4101;

Table 1 Characteristics of the 20 patients (mean (SD)
Table 1
values)

Age (years)

$\mathrm{FEV}_{1} / \mathrm{FVC}$

$\operatorname{MIP}\left(\mathrm{cm} \mathrm{H}_{2} \mathrm{O}\right)$

Arterial pH

$\mathrm{PaO}_{2}(\mathrm{~mm} \mathrm{Hg})$

$\mathrm{PaCO}_{2}(\mathrm{~mm} \mathrm{Hg})$

$63 \cdot 5(5 \cdot 24)$
$28 \cdot 3(10 \cdot 3)$

$28 \cdot 3(10 \cdot 3)$
$38 \cdot 2(9 \cdot 3)$

$64 \cdot 2(22 \cdot 3)$

$7.33(0.04)$

$48 \cdot 2(8 \cdot 03)$ $62.9(13.5)$

$\mathrm{FEV}_{1}$-forced expiratory volume in one second; FVC forced vital capacity; MIP-maximal inspiratory pressure $\mathrm{PaO}_{2}, \mathrm{PaCO}_{2}$-arterial oxygen and carbon dioxide tension. Conversion to SI units $-1 \mathrm{~cm} \mathrm{H}_{2} \mathrm{O}=0.1 \mathrm{kPa} ; 1 \mathrm{~mm} \mathrm{Hg}=$ $0.133 \mathrm{kPa}$. 
Table 2 Mean (SD) changes in arterial blood gas tensions and maximal inspiratory pressure (MIP) after negative pressure ventilation and rest alone (control day)

\begin{tabular}{|c|c|c|c|c|}
\hline & \multicolumn{2}{|c|}{ Negative pressure ventilation } & \multicolumn{2}{|l|}{ Control day } \\
\hline & Before & After & Before & After \\
\hline $\begin{array}{l}\mathrm{MIP}\left(\mathrm{cm} \mathrm{H}_{2} \mathrm{O}\right) \\
\text { Arterial pH } \\
\mathrm{PaO}_{2}(\mathrm{~mm} \mathrm{Hg}) \\
\mathrm{PaCO}_{2}(\mathrm{~mm} \mathrm{Hg}) \\
\mathrm{A}-\mathrm{aDO}_{2}(\mathrm{~mm} \mathrm{Hg})\end{array}$ & $\begin{array}{l}68 \cdot 1(21 \cdot 6) \\
7 \cdot 32(0 \cdot 04) \\
48 \cdot 4(7 \cdot 4) \\
60 \cdot 6(12 \cdot 2) \\
27 \cdot 8(9 \cdot 8)\end{array}$ & $\begin{array}{l}74.8(20.3)^{\star} \\
7.38(0.03)^{\star} \\
47.6(8 \cdot 2) \\
50.9(8 \cdot 9)^{\star} \\
39 \cdot 1(7 \cdot 8)^{\star}\end{array}$ & $\begin{array}{c}69.4(22 \cdot 4) \\
7 \cdot 33(0 \cdot 04) \\
47 \cdot 8(8 \cdot 1) \\
59 \cdot 8(10 \cdot 9) \\
29 \cdot 9(8 \cdot 8)\end{array}$ & $\begin{array}{c}70.9(22) \\
7.34(0.04) \\
48.9(9.4) \\
57.5(8.06) \\
29.9(11)\end{array}$ \\
\hline
\end{tabular}

${ }^{\star} \mathrm{p}<0.05$ in the comparison of before and after.

$\mathrm{A}-\mathrm{aDO}$-Alveolar-arterial oxygen pressure difference; other abbreviations as in table 1.

Conversion to SI units: $1 \mathrm{~cm} \mathrm{H} \mathrm{H}_{2} \mathrm{O}=0.1 \mathrm{kPa} ; 1 \mathrm{~mm} \mathrm{Hg}=0.133 \mathrm{kPa}$.

Boehringer Laboratories, Wynnewood, Pennsylvania) during maximal inspiratory efforts in a quasi-static condition at residual volume. The value obtained from the best of 10 efforts was used. ${ }^{6}$ Arterial blood gas tensions were determined with the patient supine and breathing room air (IL-1302, Instrumentation Laboratories, Milan, Italy). The alveolararterial oxygen pressure difference $\left(\mathrm{A}-\mathrm{aDo}_{2}\right)$ was calculated by using an approximation of the alveolar air equation

$$
\mathrm{PAO}_{2}=\mathrm{PIO}_{2}-\left(\frac{\mathrm{PaCO}_{2}}{0.8}\right)
$$

Patients were studied on two consecutive days after blood gas and MIP measurements. They underwent in random order negative pressure ventilation for six hours in a ponchowrap (Pulmo-wrap Lifecare Portable Ventilator, Lafayette, Colorado) or rest in bed (control day). Minute ventilation was not measured. All patients received the same medication during the two study days. Oxygen therapy was withdrawn for one hour before and during each study. Ten minutes after the end of negative pressure ventilation the MIP and blood gas tensions were measured again. Negative pressure ventilation was performed with a portable ventilator

$\underset{(\mathrm{mm} \mathrm{Hg})}{\mathrm{PacO}_{2}}$

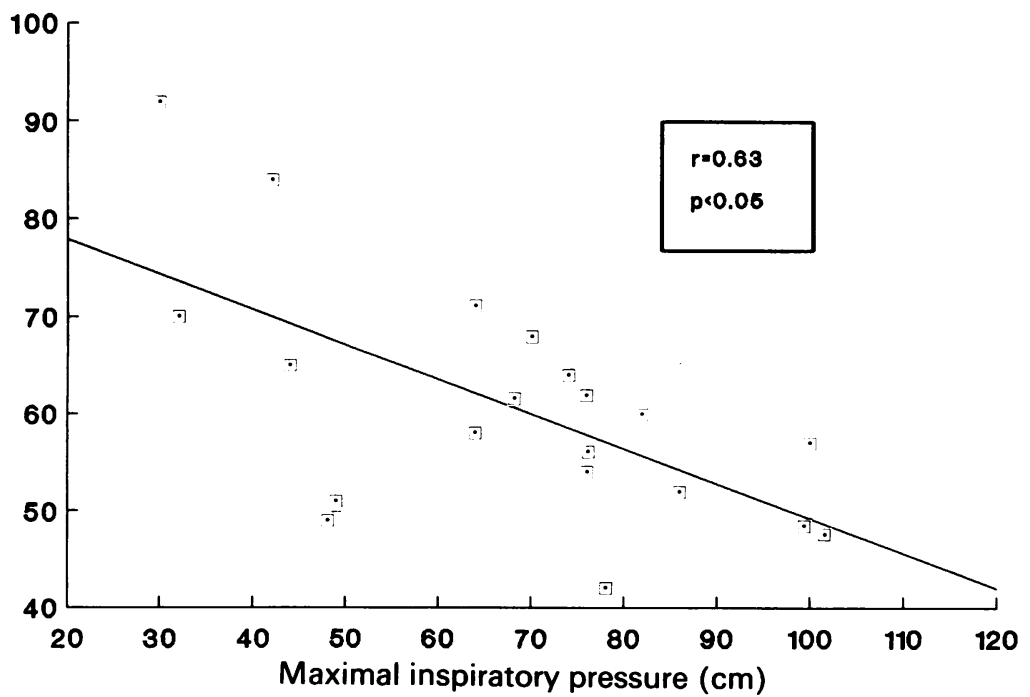

Relation between arterial carbon dioxide tension $\left(\mathrm{PaCO}_{2}\right)$ and maximal inspiratory pressure $(M I P)$ at time of initial assessment $(r=0.63, p<0.05) .1 \mathrm{~mm} \mathrm{Hg}=0.133$ $\mathrm{kPa} ; 1 \mathrm{~cm} \mathrm{H}_{2} \mathrm{O}=0.1 \mathrm{kPa}$.
(Lifecare model 170-C). Respiratory rate and the negative pressure setting of the respirator were adjusted until the patient felt comfortable (usually a respiratory rate of 20-25 breaths/min and a negative pressure of -25 to $-30 \mathrm{~cm} \mathrm{H}_{2} \mathrm{O}$ ). At the end of the negative pressure ventilation period the patients were asked about tolerance. They were classified as showing good tolerance if they thought they had slept or felt very relaxed during the procedure. Patients who complained of discomfort during the use of the negative pressure ventilation or who were thought by the technician to be uncomfortable were classified as intolerant.

Results are shown as means with standard deviations in parentheses. Comparisons between baseline and follow up measurements were made with the paired $t$ test. Differences were considered statistically significant at $\mathrm{p}<0.05$.

\section{Results}

The pulmonary function characteristics of the patients are shown in table 1 . There were no significant differences in $\mathrm{FEV}_{1}, \mathrm{MIP}$, or arterial blood gas tensions between the negative pressure ventilation day and the control day.

Mean values of MIP and blood gases before and after the six hours of negative pressure ventilation or control day are shown in table 2 . After negative pressure ventilation the MIP and $\mathrm{A}-\mathrm{aDO}_{2}$ increased significantly-from a mean (SD) of $68.1(21.6)$ to $74.8(20.3) \mathrm{cm} \mathrm{H}_{2} \mathrm{O}$ (p < 0.05) for MIP and from 27.8 (9.6) to 39.1 $(7.8) \mathrm{mm} \mathrm{Hg}(\mathrm{p}<0.05)$ for $\mathrm{A}-\mathrm{aDo}_{2} . \mathrm{PaCO}_{2}$ decreased from $60.6(12.2)$ to $50.9(8.9) \mathrm{mm} \mathrm{Hg}$ $(\mathrm{p}<0.05)$. No significant changes were observed in $\mathrm{PaCO}_{2}$ after negative pressure ventilation. There were no significant changes in any of the variables studied during the control day.

The figure shows a significant relation between baseline $\mathrm{PaCO}_{2}$ and MIP on the first study day $(r=0.63, p<0.05)$. In patients with a baseline $\mathrm{PaCO}_{2}$ above $70 \mathrm{~mm} \mathrm{Hg}$ mean (SD) MIP was $42.0(15.57) \mathrm{cm} \mathrm{H}_{2} \mathrm{O}$; in those with a baseline $\mathrm{PaCO}_{2}$ below $70 \mathrm{~mm}$ HG MIP was $74.73(17.73) \mathrm{cm} \mathrm{H}_{2} \mathrm{O}$. Patients with a baseline $\mathrm{PaCO}_{2}$ above $60 \mathrm{~mm} \mathrm{Hg}$ had a fall in $\mathrm{PaCO}_{2}$ of $13.2(7 \cdot 1) \mathrm{mm} \mathrm{Hg}$ after negative pressure ventilation, whereas those with a baseline value below $60 \mathrm{~mm} \mathrm{Hg}$ showed a smaller fall in $\mathrm{PaCO}_{2}$ of $6.2(2.7) \mathrm{mm} \mathrm{Hg}$ $(p<0.05)$. Although all patients completed the study, six complained of discomfort from the negative pressure ventilation. The 14 who tolerated the negative pressure ventilation showed a greater increase in MIP and $\mathrm{A}-\mathrm{aDO}_{2}$ than the six patients who did not tolerate it well (table 3). They also showed a significant reduction in $\mathrm{PaCO}_{2}$ after negative pressure ventilation. Patients who tolerated negative pressure ventilation poorly did not show any significant change in the variables studied after negative pressure ventilation. No clinical evidence of upper airway obstruction was observed during the study. 
Table 3 Mean (SD) maximal inspiratory pressure (MIP) and arterial blood gas tensions before and after negative pressure ventilation according to whether this was tolerated well or not

\begin{tabular}{|c|c|c|c|c|}
\hline & \multicolumn{2}{|c|}{ Good tolerance ( $n=14)$} & \multicolumn{2}{|c|}{ Poor tolerance $(n=6)$} \\
\hline & Before & After & Before & After \\
\hline $\mathrm{MIP}\left(\mathrm{cm} \mathrm{H}_{2} \mathrm{O}\right)$ & $64 \cdot 2(22 \cdot 4)$ & $73 \cdot 8(22 \cdot 1)^{\star}$ & $77 \cdot 1(18 \cdot 2)$ & $77 \cdot 1(17)$ \\
\hline Arterial $\mathrm{pH}$ & $7 \cdot 33(0 \cdot 04)$ & $7.39(0.03)^{\star}$ & $7 \cdot 34(0.04)$ & $7 \cdot 37(0.04)$ \\
\hline $\mathrm{PaO}_{2}(\mathrm{~mm} \mathrm{Hg})$ & $48 \cdot 2(8 \cdot 03)$ & $48 \cdot 0(8 \cdot 8)$ & $48 \cdot 8(6 \cdot 4)$ & $46 \cdot 8(7 \cdot 1)$ \\
\hline $\mathrm{PaCO}_{2}(\mathrm{~mm} \mathrm{Hg})$ & $62.9(13.6)$ & $51 \cdot 7(9 \cdot 8)^{\star}$ & $55 \cdot 3(6 \cdot 4)$ & $49 \cdot 2(7 \cdot 2)$ \\
\hline $\mathrm{A}-\mathrm{aDO} \mathrm{O}_{2}(\mathrm{~mm} \mathrm{Hg})$ & $24.9(10 \cdot 1)$ & $39 \cdot 8(7 \cdot 5)^{\star}$ & $33 \cdot 2(6 \cdot 2)$ & $38 \cdot 1(8 \cdot 9)$ \\
\hline
\end{tabular}

${ }^{\star} \mathrm{p}<0.05$ in the comparison of before and after.

Abbreviations as in tables 1 and 2 .

Conversion to SI units: $1 \mathrm{~cm} \mathrm{H} \mathrm{H}_{2} \mathrm{O}=0.1 \mathrm{kPa} ; 1 \mathrm{~mm} \mathrm{Hg}=0.133 \mathrm{kPa}$

\section{Discussion}

In this study on the effects of negative pressure ventilation in patients with an exacerbation of their chronic obstructive lung disease respiratory muscle strength and $\mathrm{PaCO}_{2}$ improved but $\mathrm{PaO}_{2}$ did not. The patients who tolerated negative pressure ventilation poorly were those who improved least.

Jameson et al ${ }^{7}$ in 1959 placed some patients with chronic obstructive lung disease on negative pressure ventilation for periods of hours or days. Most showed a fall in $\mathrm{PaCO}_{2}$ and a rise in $\mathrm{PaO}_{2}$. More recently, attention has been directed not only to the arterial blood gases but also to respiratory muscle function. ${ }^{1289}$ It has been suggested that a reduction in $\mathrm{PaCO}_{2}$ and improvement in respiratory muscle function may be secondary to reversal of respiratory muscle fatigue. The improvement in respiratory muscle function can even be produced with brief ventilation (three hours). ${ }^{3}$

Our study was conducted during an exacerbation of respiratory symptoms whereas previous studies were carried out in stable patients. The apparent lack of effect of external ventilation on $\mathrm{A}-\mathrm{aDO}{ }_{2}$ and $\mathrm{PaO}_{2}$ may be explained on the basis of different factors working alone or in combination: (1) when the poncho wrap was removed carbon dioxide pressure would tend to rise slowly; the period of relative hypoventilation would account for the blood gas tensions we recorded. (2) Alterations in the ventilation-perfusion relationship might have occurred immediately after the withdrawal of negative pressure ventilation. This phenomenon has been seen in chronic obstructive lung disease during the weaning period after positive pressure ventilation. ${ }^{10}$

Like Zibrak et al, ${ }^{5}$ we found that a poncho wrap negative pressure ventilation system is poorly tolerated by some patients. In these patients (six out of 20) there were no significant improvements in blood gas tensions and MIP. These results emphasise the importance of obtaining an adequate matching of patients with the poncho wrap ventilator. Synchrony between respiratory muscles and the ventilator probably favours tolerance, whereas dissociation between spontaneous and ventilator pacemakers might be responsible for discomfort and poor negative pressure ventilation tolerance. Recently it has been shown that inspiratory diaphragmatic activity ceases almost completely in trained healthy subjects when they are well adapted to a negative pressure ventilator. In contrast, in patients with airflow obstruction unfamiliar with the respirator negative pressure ventilation does not suppress the electrical activity of the diaphragm. In some patients better adaptation to the ventilator has been obtained by asking them to relax. ${ }^{11}$ All our patients were unfamiliar with the ventilator so the differences in adaptation to negative pressure ventilation were not due to differences in familiarisation with the procedure. The substantial improvement in muscle strength in our well adapted patients was probably the consequence of a partial or total relaxation of respiratory muscles during negative pressure ventilation. Other factors, however, such as the influence of a reduction of $\mathrm{PaCO}_{2}$ in muscle strength and changes in lung volumes and in the position of inspiratory muscles during assisted ventilation, may also account for differences in MIP measurements in well and poorly adapted patients. Furthermore, the poorly adapted patients may have cooperated less well in the measurement of MIP after negative pressure ventilation. Our results suggest that negative pressure ventilation can be applied to patients with an exacerbation of chronic obstructive pulmonary disease with beneficial effects on respiratory muscle strength and $\mathrm{PaCO}_{2}$. Only well adapted patients obtained substantial benefit, so a better understanding of the mechanisms of patient-ventilator coupling will be needed before negative pressure ventilation can be recommended as a routine treatment in the management of exacerbations of chronic obstructive pulmonary disease.

This study was supported by a grant from Sociedad Española de Patologia Respiratoria (SEPAR).

1 Braum NTM, Marino WD. Effect of daily intermittent rest of respiratory muscles in patients with severe chronic airflow limitation (CAL). Chest 1985;85(suppl):59-60.

2 Rochester D, Braun N, Laine S. Diaphragmatic energy expenditure in chronic respiratory failure; the effect of assisted ventilation with body respirators. $A m \mathrm{~J}$ Med 1977;63:223-32.

3 Cropp A, Dimarco F. Effects of intermittent negative pressure ventilation on respiratory muscle function in pressure ventilation on respiratory muscle function in
patients with severe chronic obstructive pulmonary disease. Am Rev Respir Dis 1987;135:1056-61.

4 Gutierrez M Beroiza T, Contreras G, et al Weekly cuirass ventilation improves blood gases and inspiratory muscle strength in patients with chronic air-flow limitation and hypercapnia. Am Rev Respir Dis 1988;138:617-23.

5 Zibrak JD, Hil NS, Federman EC, Kwa SL, O'Donnell C. Evaluation of intermittent long-term negative-pressure ventilation in patients with severe chronic obstructive pulmonary disease. Am Rev Respir Dis 1988;138:1515-8.

6 Fiz JA, Montserrat JM, Picado C, Plaza V, Agusti-Vidal A. How many manoeuvres should be done to measure maximal inspiratory mouth pressure in patients with chronic airflow obstruction? Thorax 1989;44:419-21.

7 Jameson AG, Ferrer MI, Harvey RM. Some effects of mechanical respirators upon respiratory gas exchange and ventilation in chronic pulmonary emphysema. Am Rev Respir Dis 1959;80:S10-21.

8 Garay $S$, Turini G, Goldring R. Sustained reversal of chronic hypercapnia in patients with alveolar hypoventilation syndromes; long term maintenance with noninvasive nocturnal mechanical ventilation. Am J Med $1981 ; 62 \cdot 270-4$.

9 Marino W, Braun N. Reversal of the sequelae of respiratory muscle fatigue by intermittent mechanical ventilation (abstract). Am Rev Respir Dis 1982;125(part 2):85.

10 Torres A, Reyes A, Roca J, Wagner PD, Rodriguez-Roisin $R$. Ventilation-perfusion mismatching in chronic obstructive pulmonary disease during ventilator weaning. Am Rev Respir Dis 1989;140:1246-50.

11 Rodenstein DO, Stanescu DC, Cuttita G, Liistro G Veriter $C$. Ventilatory and diaphragmatic EMG responses to negative-pressure ventilation in airflow obstruction. $J$ Appl Physiol 1988;65:1621-6. 